\title{
MULTIPLE CONTROLS OF COMMUNITY STRUCTURE AND DYNAMICS IN A SUBLITTORAL MARINE ENVIRONMENT
}

\author{
Bernat Hereu, ${ }^{1,3}$ Mikel Zabala, ${ }^{1}$ and Enric Sala ${ }^{2}$ \\ ${ }^{1}$ Departament d'Ecologia, Facultat de Biologia, Universitat de Barcelona, Diagonal 645, 08028 Barcelona, Spain \\ ${ }^{2}$ Centre d'Estudis Avançats de Blanes, Consejo Superior de Investigaciones Cientificas, 17300 Blanes, Spain
}

\begin{abstract}
The structure and dynamics of ecological communities can be determined by both top-down (e.g., predation) and bottom-up (e.g., energy inputs) processes, which can act synergistically and across spatial and temporal scales. Here we aimed at understanding the role of multiple controls in a Mediterranean rocky sublittoral marine community that harbors a diverse algal community and strongly interacting herbivores, and which is subject to marked seasonality in energy inputs. We conducted an experiment by manipulating densities of the major consumers of benthic algae (fishes and sea urchins) in $\sim 100-\mathrm{m}^{2}$ enclosures in a marine reserve, and monitored algal assemblages over two and a half years. Most algae showed a marked annual cycle, with a biomass peak in late spring/summer and low biomass in winter, following seasonal fluctuations in resource availability, indicating the existence of bottom-up processes. Sea urchins reduced the abundance of most algal species, indicating the existence of top-down processes. The effect of fish grazing on algal abundances was significantly weaker. Sea urchin grazing was inhibited when predatory fish were present. Multivariate analysis showed that the interaction between seasonal resource inputs and herbivory induced the formation of algal assemblages characterized by different species abundances. The organization of algal assemblages was determined by the synergistic interaction between top-down and bottom-up processes: top-down control regulated total algal abundance, while bottom-up control determined seasonal fluctuations.
\end{abstract}

Key words: algae; bottom-up processes; fish; herbivory; omnivory; seasonality; sea urchins; top-down processes.

\section{INTRODUCTION}

One of the key issues in ecology is the role of resources (bottom-up; Fretwell 1977) vs. predator (top-down; Hairston et al. 1960) control in the structure and dynamics of populations and communities. Bottom-up and top-down forces do not act in isolation, they vary within and among systems (e.g., Power 1992, Menge 2000), and their relative strength in determining community structure and dynamics is context dependent (e.g., Worm et al. 2002, Hughes et al. 2003, Burkepile and Hay 2006). For instance, the effects of grazing on primary producers can vary as a function of the energy inputs into the system, the life history of species, and the food web structure (reviewed by Power 1992, Polis 1999). The important question is thus to determine under which conditions predators or resources will dominate community regulation (Hunter and Price 1992, Power 1992).

In marine benthic ecosystems, the effects of bottomup factors appear to be stronger when top-down forces are reduced, and top-down effects vary across a gradient of energy input (e.g., background productivity, water

Manuscript received 12 April 2007; revised 29 March 2008; accepted 25 March 2008. Corresponding Editor: J. J. Stachowicz.

${ }^{3}$ E-mail: hereu@ub.edu flow). A recent meta-analysis of experimental studies has shown that, although both nutrient enrichment and herbivory affect the abundance of primary producers (microalgae, macroalgae, and sea grasses), nutrient loading has stronger effects after the loss of herbivores (Burkepile and Hay 2006). Nevertheless, this general model has some variations. In the Caribbean, the loss of herbivores appears to have been more important than eutrophication in driving the shift from coral- to algaldominated reefs (Burkepile and Hay 2006). In contrast, the relative strength of herbivores vs. nutrients on temperate seas varies across a gradient of energy input. In low-productivity areas, nutrient enrichment has significant effects only when herbivores are absent, whereas in high-productivity areas the removal of herbivores has insignificant effects on the abundance of primary producers (Burkepile and Hay 2006). A study performed in a Maine estuary showed that high consumer pressure was the dominant force at sites with low water flow, while the effects of bottom-up forces (e.g., growth rates and recruitment) became dominant at high-flow sites (Leonard et al. 1998). In addition, the effects of consumers on algal communities shift across a gradient of productivity, since removing consumers decreases diversity in high-productivity areas but increases diversity in low-productivity areas (Worm et al. 2002). 
The conclusions from experimental studies are supported by large-scale descriptive studies in high-productivity temperate systems where algal and invertebrate abundance is mostly determined by variation in background productivity (Dayton et al. 1992, 1999), and by the intermittence of upwelling (Menge et al. 2003, Nielsen and Navarrete 2004). Nevertheless, community studies at large spatial and temporal scales are scarce in the literature; hence the link between the small-scale effects of herbivores and productivity and the long-term dynamics of algal assemblages is still largely undetermined.

Although there are a number of studies where nutrient availability and grazer abundance have been manipulated at small spatial scales (cages $<1 \mathrm{~m}^{2}$ ) and short temporal scales (for a review see Burkepile and Hay 2006), it is difficult to manipulate resource availability at larger scales in sublittoral systems. The comparison of sites located far apart and exposed to different environmental conditions (e.g., different degrees of upwelling) can provide some clues about the role of bottom-up processes (Bustamante et al. 1995, Broitman et al. 2001, Menge et al. 2003), although geographic distance can introduce uncontrolled factors that may confound the experimental results.

In this study we aimed at determining the role of topdown and bottom-up processes in the regulation of the structure of a Mediterranean sublittoral assemblage at scales larger than previously used, by manipulating fishes vs. urchins while monitoring physico-chemical data and determining community structure of the algal community. This process generated many logistical and conceptual challenges. First, we conducted a fieldintensive experiment to manipulate the abundance of herbivores in large exclosures during two and a half years. Second, it was impractical to manipulate experimentally the most important bottom-up factors that determine algal growth (light, nutrient concentration, and temperature [Ballesteros 1989, 1992]) at large scales in the field, and in a marine reserve. Thus, we monitored these variables during the study using the natural seasonal cycles as a proxy to determine the bottom-up effects on the algal assemblage. The Mediterranean is a highly seasonal sea (see Plate 1), where the combination of major environmental resources for algal growth is optimal in spring, when algae exhibit a peak in growth and biomass, and lowest in winter, when algae exhibit a low in biomass and growth (Ballesteros 1991, 1992).

\section{Materials and Methods}

\section{Study sites and assemblages}

The study was carried out in the Medes Islands Marine Reserve $\left(42^{\circ} 16^{\prime} \mathrm{N}, 03^{\circ} 13^{\prime} \mathrm{E}\right)$, Catalonia, northwest Mediterranean Sea (Hereu 2006), where fishing has been prohibited since 1983 (Appendix A). Our study sites were small coves with large boulders and south-southwest orientation. The study was carried out on algal assemblages at 5-8 $\mathrm{m}$ depth that are composed of distinct strata: an erect stratum with several species of algae, both annual and perennial, a stratum of understory algae, and an encrusting stratum. This algal assemblage is composed of up to 100 species, and exhibits marked seasonal cycles of algal biomass (Ballesteros 1989, 1992, Sala and Boudouresque 1997).

Fish assemblages at the study site are described in García-Rubies and Zabala (1990) and García-Rubies (1996, 1999); fish diets and grazing impacts in Sala and Ballesteros (1997) and Sala and Boudouresque (1997). The major benthic-feeding fishes are sparids, mainly Diplodus spp.; Sarpa salpa, the major strictly herbivorous fish, is also present in great abundance (Appendices B and C). The sea urchin Paracentrotus lividus is the most important grazer in this system, and at high densities it can turn complex algal assemblages into coralline barrens by grazing (Verlaque 1987). Overfishing of sea urchin predators can result in increases of sea urchin abundance and subsequently in the formation of coralline barrens (Sala et al. 1998).

\section{Experimental design}

To determine the relative impacts of fish and sea urchin grazing on algal assemblages, we conducted a grazer exclusion experiment from June 1998 to September 2000. We manipulated the density of herbivorous/ omnivorous fishes and the sea urchin Paracentrotus lividus, the most abundant sea urchin in the region (Sala et al. 1998). Grazer exclusions were replicated in three experimental coves (Sant Istiu, Cova de la Reina, and Racó del Portitxol; Appendix A). The experiment consisted of four combinations of fishes and sea urchins: no grazers (Controls, C), only sea urchins present (U), only fish present $(\mathrm{F})$, and both sea urchins and fish present (FU) (Fig. 1; see also Hereu 2006). Fish exclusion treatments were built by closing small coves $\left(70-110 \mathrm{~m}^{2}\right)$ with nets. Polypropylene trawler nets of 2.5 $\mathrm{cm}$ mesh size, 6-8 $\mathrm{m}$ depth and 11-16 $\mathrm{m}$ length were attached to a steel cable anchored into the substratum using autoexpanding nails. The upper part of the net was kept on the surface continuously using plastic buoys. Roofless herbivore exclusion nets have negligible lightshading effects. The exclusion nets were cleaned and checked weekly, and replaced whenever necessary for repairs and more thorough cleaning. Enclosures were checked every other day for large fishes, which were removed when they occasionally migrated into the exclusion area.

Although water flow might differ inside and outside the small coves, the sampling plots were very close, separated only by the large net, and no significant differences in environmental conditions between plots were expected. Increased densities of micrograzers represent a potentially confounding factor in the interpretation of experimental manipulations involving caging treatments, but the mesh size of our exclosures diminishes the likelihood of such artifacts usually associated with small cages that were previously used 
(Sala 1997a). The mesh size of the nets allowed free passage to juvenile sparids and several small labrids that are carnivores (Sala 1997b). The abundant Coris julis and other small wrasses, such as Symphodus ocellatus, Symphodus roissali, or Thalassoma pavo, predators of gastropods, small crustaceans, and juvenile echinoderms $(0.2$ to $1 \mathrm{~cm})$ (Sala $1997 b$, Hereu et al. 2004), moved freely through the exclusion areas and were commonly observed feeding within exclosures. The experiment thus tested the effects of adult herbivorous (mainly Sarpa salpa), omnivorous (mainly Diplodus sargus, D. vulgaris, D. puntazzo), and larger carnivorous (such as Labrus merula or Symphodus tinca) fishes only. See Appendix B for a list of the fishes censused in this study.

To establish the treatments with and without sea urchins, we built $16-\mathrm{m}^{2}$ roofless enclosures inside and outside the exclusion coves using $10 \mathrm{~cm}$ tall plastic fences (mesh size of $2 \mathrm{~cm}$ ) supported by steel rods anchored into the substratum. Because algal assemblages were not sampled near the edges of the enclosures and these roofless fences did not interfere with light and water movement (Sala and Boudouresque 1997), we assumed that caging artefacts were negligible. To establish the treatments without sea urchins, all urchins from several large boulders in and outside the coves were removed. These boulders were also fenced to prevent recolonization by urchins. To ensure that there were no invasions of urchin-free treatments or escape of sea urchins from inclusion treatments, weekly observations were made inside and around the plots, and densities were manipulated when necessary. Sea urchin densities similar to those found before the experiment $(\sim 12$ urchins $/ \mathrm{m}^{2}$ ) and with similar size distributions were established and maintained in the sea urchin enclosure throughout the study (Appendix D).

\section{Quantification of the structure of algal assemblages}

To determine the effects of the experimental treatments on the algal assemblages we monitored algal composition and abundance monthly (weather permitting) from May 1998 to September 2000. The monthly sampling interval was intended to incorporate the seasonality of algal dynamics in the region (Ballesteros 1991, Sala and Boudouresque 1997). Algal cover was quantified using $25 \times 25 \mathrm{~cm}$ quadrats divided into $255 \times$ $5 \mathrm{~cm}$ subquadrats (Sala and Ballesteros 1997). Four replicate quadrats were randomly placed at each treatment and site, and the percentage cover of each taxon was estimated as the percentage of the number of subquadrats where a taxon was present relative to the total number of subquadrats sampled. Due to the extreme diversity of Mediterranean algal communities at small spatial scales (Verlaque 1987), the $625-\mathrm{cm}^{2}$ sampling area fulfilled the requirements of minimum area for quantification of community structure (Ballesteros 1992).

Sea urchin density and size distribution were quantified monthly using randomly placed $1-\mathrm{m}^{2}$ quadrats $(n=$

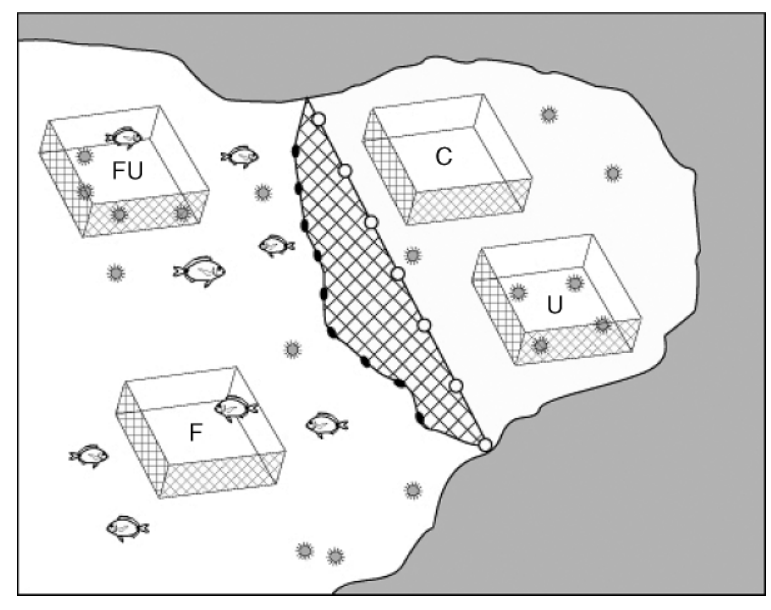

FIG. 1. The design of one set of experimental enclosures in which absence/presence of fishes and sea urchins were controlled, allowing combinations of sea urchins and fish presence for treatments. Key to abbreviations: C, controls (fishes and urchins absent); U, only urchins present; F, only fishes present; FU, both fishes and urchins present.

4 per site and treatment). The abundance and size of herbivorous and omnivorous fish were determined by visual censuses using the fixed-point method (HarmelinVivien et al. 1985). A diver stopped at a point chosen haphazardly and identified, counted, and estimated the size of all fishes within a radius of $6 \mathrm{~m}$. Because the size of the enclosures did not allow us to conduct spatially independent counts within the same day, we conducted one fish count each day during four days within a month to obtain a measure of the variability in fish abundance. The density of most benthic-feeding fishes in the Medes Islands does not show significant variability through the year (Garcia-Rubies 1996); hence, we conducted censuses once a year (in July) from 1998 to 2000. Fish biomass was estimated using length-mass equations (Garcia-Rubies 1996, Bayle et al. 2001; E. Sala, unpublished data).

To ensure that all sites had algal communities with similar starting composition and structure, we quantified algal abundance at all sites and tested for differences between sites prior to building the experimental treatments. To test for differences in the structure of algal communities, we used a nonparametric Analysis of Similarity (ANOSIM) (Clarke 1993) including all major algal species (Appendix C). We did not find significant differences in algal abundance and community structure between sites (global $R=0.14 ; P=0.21$ ). There were no significant differences in sea urchin density between sites prior to manipulation (mean density $=10.41$ individuals $/ \mathrm{m}^{2}$; ANOVA $\left.F_{5,54}=0.62, P=0.68\right)$.

\section{Data analysis}

To determine the effects of the different treatments on algal cover, we conducted a repeated-measures analysis 


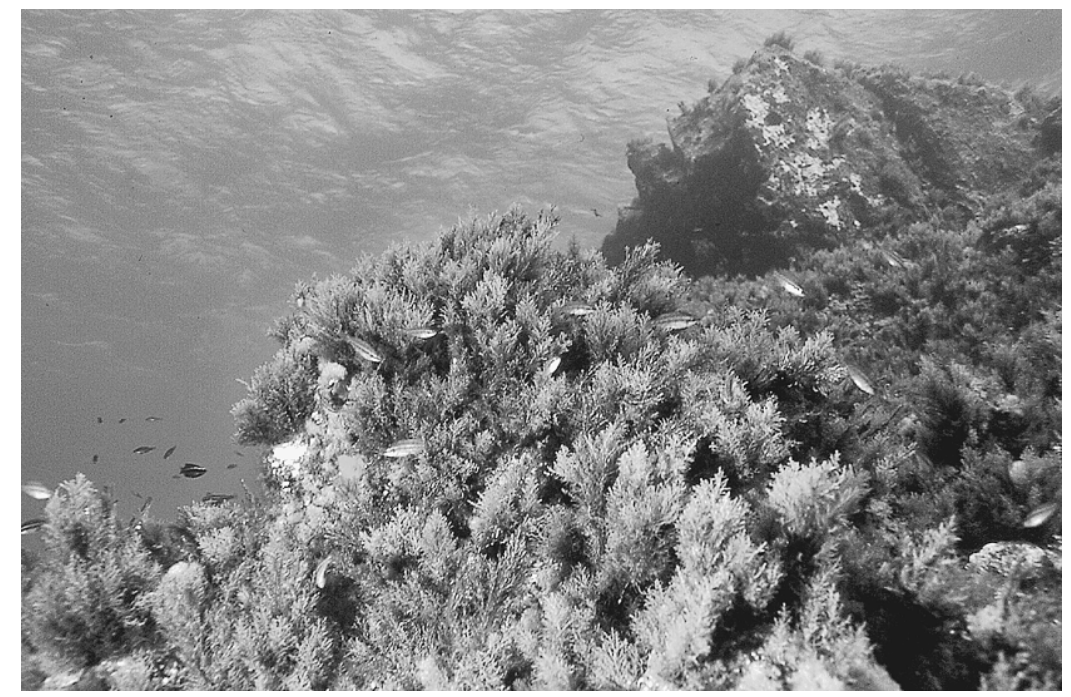

Plate 1. A typical Mediterranean rocky subtidal community, covered by a forest of Cystoseira balearica, with some barren patches created by sea urchins, and with small labrid fish. The high water transparency is characteristic of this oligotrophic and highly seasonal sea. A color version of this photo is available in the October issue of the Bulletin of the Ecological Society of America 89(4):391. Photo credit: B. Hereu.

of variance (RMANOVA) for each species. Treatment $(\mathrm{C}, \mathrm{U}, \mathrm{F}, \mathrm{FU})$ as fixed factor was the between-subject factor, and time (i.e., sampling events) the repeatedmeasure (within subject) factor. The assumption of homogeneity of variances was checked using Cochran's $C$ test and data transformations were performed when necessary. To test whether the data matrix fulfilled circularity, we used Mauchly's test of sphericity. When sphericity was violated, we made a Huynh-Feldt adjustment by multiplying the numerator and denominator degrees of freedom by epsilon $(\Sigma)$ (von Ende 1993), after which $F$ values and probabilities were calculated.

A Tukey's hsd post hoc test was performed to test for differences among treatments. Although this simple ANOVA design may be less powerful than others, we used it because it was impractical to enclose more replicate coves to include a completely orthogonal design. Nevertheless, the results were conspicuous enough to distinguish the effects of each treatment. The relative effect size of the experimental factors was calculated as omega squared $\left(\omega^{2}\right)$ (Graham and Edwards 2001). For the highly seasonal species that are only present during a short period of the year, only data collected during the growth period were used in the analysis to avoid a high number of zeros.

To analyze multiannual changes in the algal community in the experimental treatments, we performed an indirect gradient analysis (unconstrained ordination). To determine what analysis was appropriate we performed a detrended correspondence analysis on the algal data, and calculated the length of the gradient. The length of the gradient measures the beta diversity in community composition (the extent of species turnover) along the individual independent gradients (ordination axes) (Leps and Smilauer 2003). The length of the gradient was 1.7; thus we chose the linear method, principal components analysis (PCA). To test whether the multinormality requirement was fulfilled we computed Mahalanobis distances between each sample and the multidimensional mean of all samples, and then conducted a test of normality of the distances (Legendre and Legendre 1998). A chi-square test gave $P=0.15$, indicating that the data were multinormal. Algal species with cover $<1 \%$ or occurring in only one sample were excluded from the analysis.

To determine the relative importance of bottom-up (seasonality) vs. top-down (grazing) factors in determining the structure of the algal assemblage, relationships among algal species and environmental variables were analyzed by direct gradient analysis (Redundancy Analysis, RDA) (ter Braak 1994), using the ordination program CANOCO for Windows version 4.0 (ter Braak and Smilauer 1998). The RDA introduces a series of explanatory (environmental) variables and resembles the model of multivariate multiple regression, allowing us to determine what linear combinations of these variables determine the gradients. Fish and sea urchin abundance (as categorical variables), nitrate, nitrite, and phosphate concentration, irradiance, and surface water temperature were included as environmental variables.

Oceanographic data were obtained from the oceanographic and meteorological station of l'Estartit, a single station situated $\sim 3.2 \mathrm{~km}$ offshore and north of the Medes Islands (Appendix E; Salat and Pascual 2002). Water temperature was recorded weekly with a conductivity, temperature, depth recorder (CTD) at 0, 5, 20, 35, 50, 65, and $80 \mathrm{~m}$ since 1973 (Salat and Pascual 2002). We 
used the data from $5 \mathrm{~m}$ depth, and averaged the monthly temperatures for the analysis. Irradiance was computed from weekly Secchi disk measurements (Weinberg and Cortel-Breeman 1978). To measure nutrient concentration, we collected water samples at a single station at $5 \mathrm{~m}$ depth between the two main islands in the reserve, each month from January 1998 to December 1999, using a Niskins oceanographic bottle. Because of logistical constraints, samples in 2000 were taken every four months. The water samples were labelled and frozen, and later analyzed in the laboratory for dissolved nitrate, nitrite, and phosphate with a Technicon autoanalyzer (the Technicon Corporation is no longer in operation).

Time was included at two different scales: (1) seasons (spring, summer, fall, and winter), and (2) time elapsed since the beginning of the experiment, in years. Forward selection of environmental variables was used to ascertain the minimum set of significant variables that better explain the species data. The statistical significance of the contribution of the environmental variables to the ordination was determined using a Monte Carlo permutation test (ter Braak 1994, ter Braak and Smilauer 1998).

\section{Results}

\section{Monitoring of the experimental conditions}

Sea urchin densities in experimental treatments did not show significant changes over time, and our periodic removals maintained sea urchin abundance within exclosures near zero over the study period (ANOVA; interaction treatment $\times$ time, $F_{57,1120}=0.38, P=0.99$; time $F_{19,1120}=0.21, P=0.98$ ) (Appendix D). A total of 46 fish species were observed at the study sites (Appendix B). The abundance of the major herbivorous and omnivorous fishes was significantly different between treatments after the creation of the fish exclosures, and maintained throughout the experiment, indicating that the enclosures were successful in reducing the abundance of medium- and large-sized herbivores and omnivores (Appendix F). However, small wrasses, which can move through the nets, did not show significant differences between treatments (Appendix F).

\section{Effects of experimental factors on algal species abundance}

Algal cover followed a similar seasonal pattern for all species, with no significant interactions between time and treatment (Fig. 2; Appendix G), except for $P$. pavonica, A. acetabulum, C. elongata, L. incrustans, $M$. alternans, and turf algae. The effect of time was highly significant in almost all species, and the response of algae to grazers was highly variable (Fig. 2; Appendix H). Total algal cover showed a seasonal pattern, with an increase of cover in spring and early summer. Changes in cover of the most abundant algal species (which represent the major seasonal patterns) over the 29month study period are shown in Fig. 2; data on all other species are shown in Appendix H. Annual species had a strong production period, typically during spring (e.g., Asparagopsis armata, Dictyota dichotoma, Taonia atomaria, Colpomenia sinuosa), although a few species peaked during late summer (Padina pavonica, Acetabularia acetabulum, Ulva rigida) and winter (Laurencia obtusa, Ceramiaceae). Cover decreased significantly after the spring peak. Perennial species (such as Codium vermilara, Codium bursa, Halopteris scoparia, Halopteris filicina, Corallina elongata, Jania rubens, Zanardinia prototypus, Lithophyllum incrustans, and Mesophyllum alternans) did not show clear seasonal patterns. Some perennial species (Cystoseira sp. and C. compressa) developed seasonal canopies but also had perennial thalli that persisted during winter.

Treatments with sea urchins significantly reduced total algal cover and the cover of many species of erect algae, turf algae, and the crustose coralline Mesophyllum alternans (Fig. 2; Appendix G). In contrast, the cover of some species such as the highly seasonal Acetabularia acetabulum, the crustose coralline Lithophyllum incrustans, and turf algae increased, suggesting a facilitation effect of these species by sea urchin grazing. The effects of fishes, in contrast, were not as evident, although Padina pavonica cover was enhanced in the presence of fish (Fig. 2; Appendices $\mathrm{G}$ and $\mathrm{H}$ ).

Interaction between time and treatment for seasonal species ( $A$. acetabulum and $P$. pavonica) showed that herbivores modified their annual cycle by increasing their cover during the maximal seasonal growth period (Fig. 2; Appendices G and H). Contrarily, for perennial species the effect of herbivores was constant in time, gradually decreasing (for C. elongata and M. alternans) or increasing (for L. incrustans and turf algae) their cover during the experiment (Fig. 2; Appendix G).

The variance explained by time and treatment was variable depending on the individual species. For highly seasonal species such as Acetabularia acetabulum, Padina pavonica, Asparagopsis armata, and Dictyota dichotoma most of the variance was explained by time, while for perennial species such as Corallia elongata, Codium vermilara, Cystoseira sp., Halopteris scoparia, Jania spp., Lithophyllum incrustans, or Mesophyllum alternans, the grazing treatment explained most of the variance (Fig. 2; Appendix G). For total algal cover, the variance explained by the herbivore treatment $\left(\omega^{2}=33.23\right)$ was greater than the variance explained by time $\left(\omega^{2}=20.08\right)$ (Fig. 2; Appendix G).

\section{Effects of experimental factors on algal assemblage structure and dynamics}

The two first axes of the RDA explained $54.2 \%$ of the variance (Fig. 3). All environmental variables were statistically significant (Monte Carlo test, $P<0.01$ ). Sea urchins were strongly and negatively correlated with axis $1(r=-0.83$, Appendix I) and accounted for $27 \%$ of the analysis variance, suggesting that this axis represents 

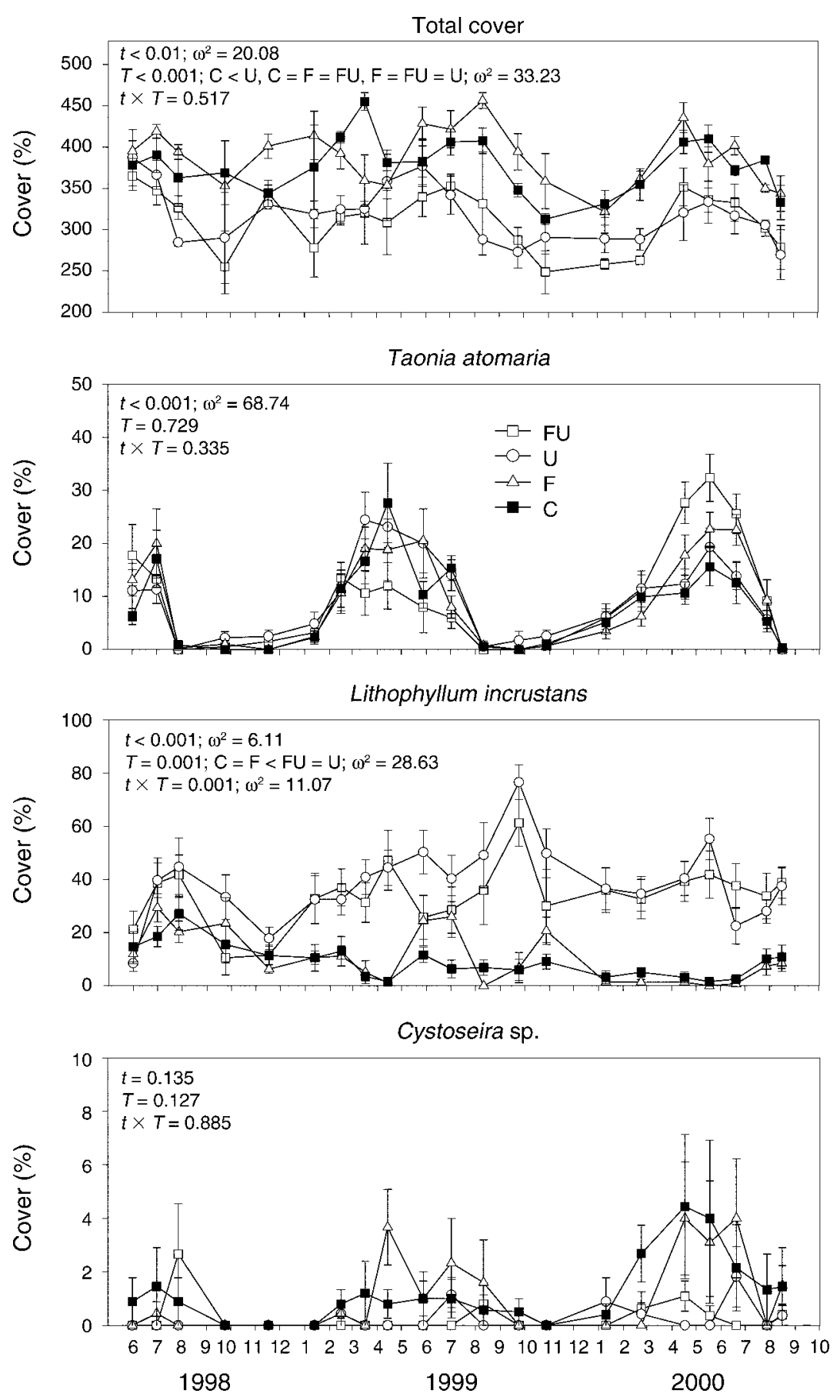

FIG. 2. Temporal variation in cover (mean $\pm \mathrm{SE}$ ) of algal species representing major life history strategies. The remainder of the species are shown in Appendix H. Total cover is expressed as the cumulative percentage of all species monitored. Levels of significance for the treatment $(T)$, time $(t)$, and treatment $\times$ time tests are presented in the text box for each graphic, as well as the results of the post hoc analysis and the relative effect size of the experimental factors $\left(\omega^{2}\right)$ (see Results). Key to abbreviations: C, controls (fishes and urchins absent); U, only urchins present; F, only fishes present; FU, both fishes and urchins present. Months are shown as January (1) through December (12).

the top-down (urchin grazing) control of algal communities. Major variables related to productivity (irradiance, temperature, and phosphate, which explained $8 \%$, $6 \%$, and $1 \%$ of the analysis variance, respectively) were significantly correlated with axis 2 , which appears to represent the bottom-up (seasonality) control of algal assemblages. Nitrate and nitrite concentrations, time, and fish (which explained $4 \%, 2 \%, 3.5 \%$, and $4.5 \%$ of the 

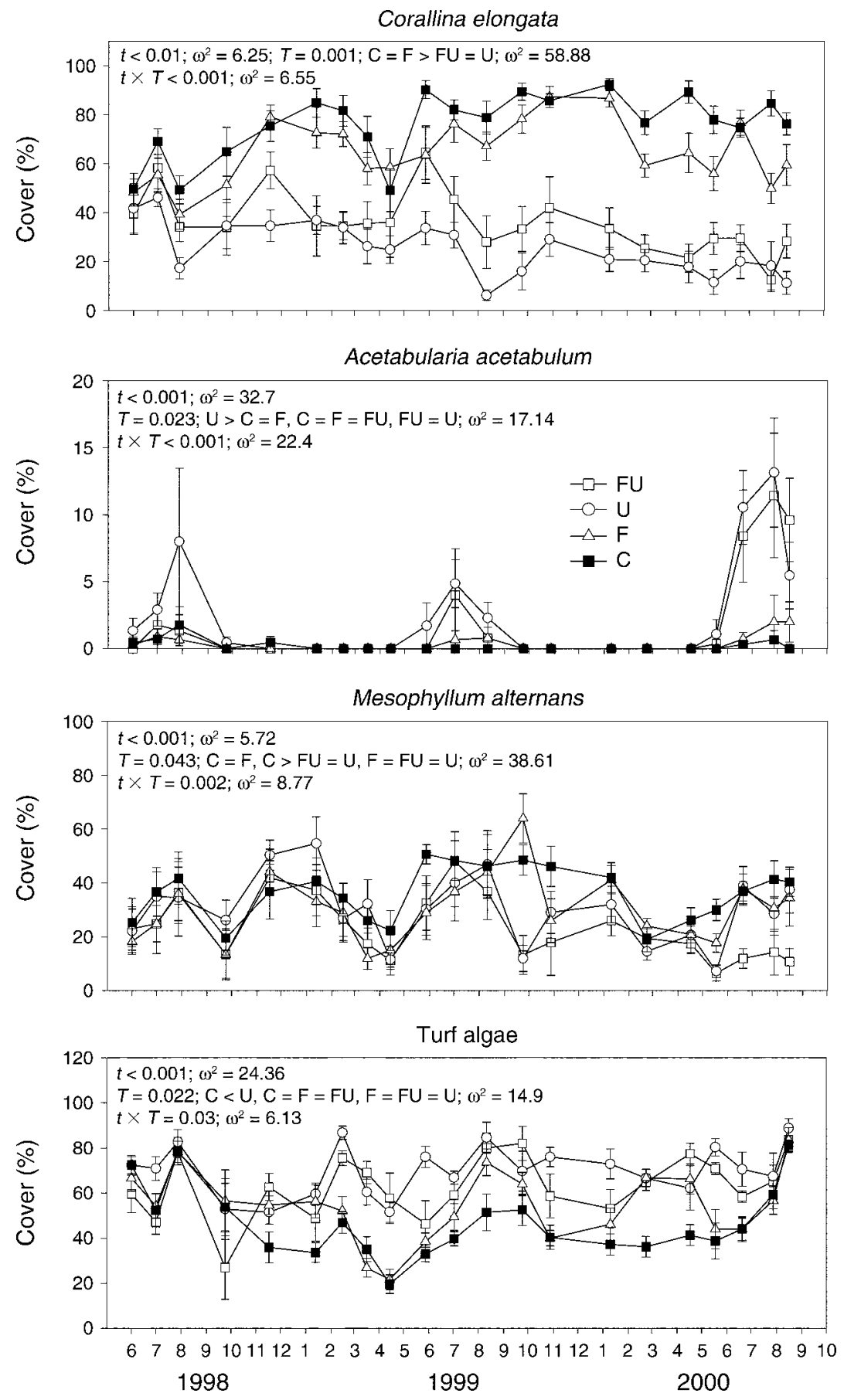

FIG. 2. Continued.

analysis variance, respectively) had no significant correlation with any of the first two axes.

The centroids of the physicochemical variables in the RDA diagram are ordered in consecutive positions that correspond to the succession of their maximum values in an annual cycle. Following the centroids in a counterclockwise direction, the diagram shows an annual pattern (Fig. 3, inset) reflecting the peaks of the environmental variables: irradiance peaks in late spring, temperature in late summer, and nutrient concentration in late fall and winter (Ballesteros 1991).

The multivariate analyses indicate that sea urchin grazing benefited grazing-resistant species such as encrusting corallines (e.g., Litophyllum incrustans) and opportunistic turf species such as Acetabularia acetabulum and Ulva rigida (Fig. 3, Appendix I). In contrast, 


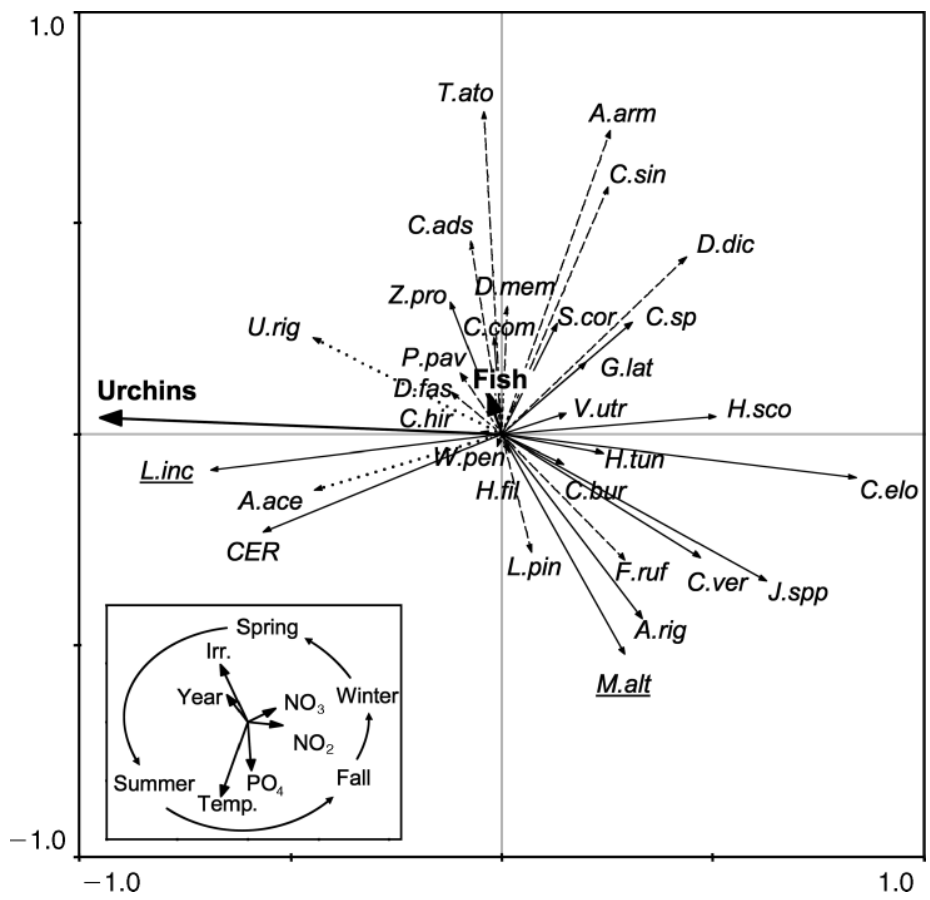

FIG. 3. Redundancy analysis (RDA) biplot showing the ordination of algal species and the contribution of sea urchins and fishes to the observed patterns. The inset graph shows the distribution of environmental variables, and the curved arrows represent an annual cycle, based on the location of the centroid of the samples collected in each season. The scale of the inset is the same (-1.0 to 1.0 on both axes). The location of seasons in the biplot was determined on the basis of the location of the centroid of the samples collected in each season. Samples were omitted for clarity. Species codes: A.ace, Acetabularia acetabulum; A.rig, Amphiroa rigida; A.arm, Asparagopsis armata; Cer, Ceramiaceae; C.hir, Cladostephus hirsutus; C.bur, Codium bursa; C.eff, Codium effusum; C.sin, Colpomenia sinuosa; C.ver, Codium vermilara; C.elo, Corallina elongata; C.ads, Cutleria adspersa; C.com, Cystoseira compressa; C.sp, Cystoseira sp.; D.dic, Dictyota dichotoma; D.fas, Dictyota fasciola; D.mem, Dictyopteris membranacea; F.ruf, Falkenbergia rufolanosa; G.lat, Gelidium latifolium; H.fil, Halopteris filicina; H.sco, Halopteris scoparia; H.tun, Halimeda tuna; J.spp, Jania spp.; L.obt, Laurencia obtusa; L.inc, Lithophyllum incrustans; M.alt, Mesophyllum alternans; P.pav, Padina pavonica; S.cor, Sphaerococcus coronopifolius; T.ato, Taonia atomaria; U.rig, Ulva rigida; V.utr, Valonia utricularis; W.pen, Wrangelia penicillata; Z.pro, Zanardinia prototypus. Growing strategies are also indicated: solid arrows indicate perennial species; dashed arrows indicate seasonal species; dotted arrows indicate ephemeral species; underlined names are encrusting coralline species. Environmental variables: Temp., temperature; Irr., irradiance; $\mathrm{NO}_{3}$, nitrate; $\mathrm{NO}_{2}$, nitrite; $\mathrm{PO}_{4}$, phosphate.

perennial species such as Corallina elongata, Halopteris scoparia, Codium vermilara, and Jania rubens were more abundant in the absence of sea urchins. Seasonal erect algae such as Taonia atomaria, Asparagopsis armata, Colpomenia sinuosa, and Dictyota dichotoma were significantly and positively related to seasonal energy inputs (Fig. 3, Appendix I). These species were weakly correlated with sea urchin presence, indicating that sea urchin grazing had stronger effects on perennial than on seasonal species.

The PCA analysis confirmed this pattern (Fig. 4). The first principal component axis (PC1) explained $39.4 \%$ of the variance and appeared to discriminate for sea urchin grazing (Fig. 4, Appendix J). The samples in the presence of sea urchins are mostly on the left of the plot, whereas the samples without sea urchins are on the right side. The second principal component axis (PC2) explained $15.6 \%$ of the variance and appeared to discriminate samples on a temporal basis. Samples from spring are on top of the plot and samples from fall at the bottom.
Because axis 2 was mainly related to seasonal variability, we compared the oscillations between treatments by testing for differences in the variance on axis 2 scores samples using an $F$ test. When comparing treatments with and without sea urchins, seasonal oscillations in treatments without sea urchins were higher $\left(F_{41,41}=2.055 ; P<0.05\right)$.

\section{Discussion}

Our study demonstrated that the effects of disturbance caused by both herbivores (top-down) and seasonality (bottom-up) had an important role in determining the structure of Mediterranean algal assemblages at different temporal scales, and that the effects of herbivores were greater than those caused by the seasonality $\left(\omega^{2}=33.23\right.$ and $\omega^{2}=20.08$, respectively). We also showed that different algal species show different responses to herbivores depending on their adaptation to seasonal fluctuations on resource limitations. These seasonal short-term processes determine the long-term structure and dynamics of algal assemblages. 


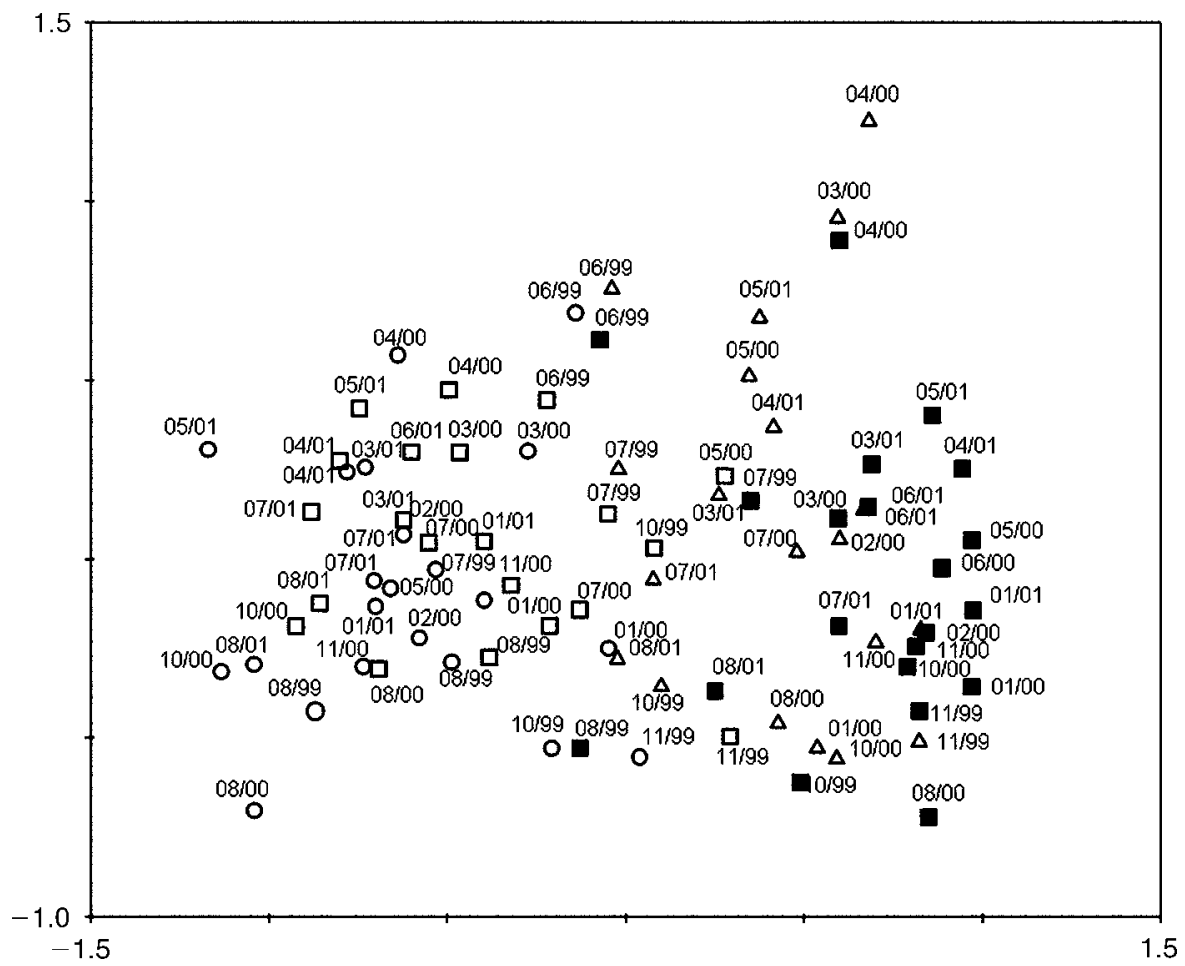

FIG. 4. Principal components analysis (PCA): scatterplot of samples. Codes for sites: solid squares, C (controls; fishes and urchins absent); triangles, F (fishes only); circles, U (urchins only); open squares, FU (fishes and urchins). Numbers represent month and year of sampling (mm/yy); that is, 04/00 means April 2000.

\section{Bottom-up processes: seasonal resource cycles}

Our results support the idea that Mediterranean algal communities show seasonal cycles of biomass (Ballesteros 1991), although herbivore abundance can modify its intensity. Our results strongly indicate that the seasonal fluctuation in algal cover is caused by the seasonal fluctuation of environmental resources and not by changes in grazing rates. Mediterranean sea urchins change their diet composition as a function of the seasonal availability of algae, but algal consumption (grazing rates) is actually maximum in spring and summer (Peirano et al. 2001, Tomas et al. 2005, Prado et al. 2007), when algal biomass and productivity is greater. This indicates that seasonal variations in grazing do not explain the observed patterns of algal abundance. Moreover, because grazing pressure is greater when algal growth is also greater, the "bottomup" effect would perhaps be larger in magnitude if the seasonal signal in grazing intensity could be removed.

Our approach of using natural seasonal cycles as a proxy for changes in bottom-up factors was not strictly an experimental manipulation, and consequently it did not allow us to discriminate between the effects of seasonality in grazing rates and the specific effects of nutrients, light, and temperature, or their interactions. However, the combination of these environmental factors occurs naturally and produces seasonal changes in algal productivity that are predictable in time
(Ballesteros 1992). We believe it is that predictable, natural combination of these factors over the seasons that matters, and not any other possible combination of these factors that could have been manipulated experimentally, but which would be nonexistent in the field. In addition, it was the only approach we could use to study natural communities on a multiannual basis and at spatial scales larger than previously used, and it helped us avoid other uncontrolled factors associated with spatial heterogeneity.

\section{Top-down processes: fish vs. sea urchin grazing}

Sea urchins are the major benthic herbivores of Mediterranean rocky sublittoral communities (Verlaque 1987, Benedetti-Cecchi and Cinelli 1995). Although fishes have been shown to influence the structure of Mediterranean algal assemblages (Sala and Boudouresque 1997, Ruitton et al. 2000), the effects of fish grazing in our experiments were weaker than sea urchin grazing. Similar results are shown in other temperate systems, where the sea urchins were the main herbivores, and fishes had a weak effect, especially compared with tropical systems (reviewed by Floeter et al. 2005).

\section{Top-down processes: trophic cascades}

Predation can regulate the abundance of major consumers of the dominant primary producers, causing trophic cascades (Pace et al. 1999, Steneck and Sala 
2005). In the Mediterranean, large densities of predatory fishes have the potential to control sea urchin populations and reduce sea urchin grazing, which in turn causes an increase in algal biomass (Sala and Zabala 1996, Sala et al. 1998). Because the density of sea urchins in our treatments was maintained artificially, we could not test whether predation by fishes controlled sea urchin abundance and consequently the structure of algal assemblages through a trophic cascade. However, in a parallel tethering experiment using the same experimental design, Hereu (2006) quantified the fish-urchin interaction and showed that the biomass of two algal species (Ulva rigida and Cystoseira sp.) consumed by sea urchins was lower in the presence of fish, probably caused by trait-mediated indirect interaction (Abrams et al. 1996). The simple presence of a predator can produce a sheltering response and lowered activity in prey (e.g., Schmitz et al. 1997, Trussell et al. 2003). In the Mediterranean, it has been shown that Paracentrotus lividus grazes on open surfaces during the day in the absence of predators, whereas most individuals are sheltered in the presence of abundant predators (Sala and Zabala 1996). When predators are abundant, $P$. lividus moves to exposed surfaces only at night, which reduces the spatial extent of grazing to about $1 \mathrm{~m}$ around the shelters (Sala 1996, Hereu 2005). We observed the same type of behavior in our FU treatment. Even when sea urchins could not shelter, their activity and movements were reduced.

\section{Top-down vs. bottom-up: structure of algal assemblages}

In rocky intertidal systems, many studies have shown that the growth of algae is limited by seasonal factors, such as grazing activity (e.g., Lubchenco and Cubit 1980, Cubit 1984), environmental stress (e.g., Underwood 1981, Kaehler and Williams 1998), and primary productivity (Cubit 1984). Seasonal oscillations of physical conditions periodically shift the net outcome that occurs between herbivory and primary production. Experiments under different upwelling regimes showed that predation rate is greater under strong upwelling than under weak upwelling conditions (Menge et al. 1997, 2004). Contrarily, Nielsen and Navarrete (2004) found a major effect of herbivores on algal biomass in low-productivity areas, but a more highly structured community with a major proportion of corticated algae in the most productive areas. Nevertheless, these contradictory results could be caused by the human removal of large grazers that can feed on corticated algae (Nielsen and Navarrete 2004). Similar findings on the community-level consequences of species-specific ecology are reported by other studies that describe the persistence of many species of grazer-resistant algae as a function of the removal of competitively dominant species that are less resistant to herbivores (Souza 1979, Lubchenco and Gaines 1981, Duffy and Hay 2000).
Our study showed both interannual and seasonal changes mediated by environmental factors and herbivory. Our treatments contained distinct groups of species whose dominance changed distinctly over time. Treatments with sea urchins were dominated by (1) species that are resistant to grazing, such as Lithophyllum incrustans, and (2) species whose seasonal and opportunistic growth can compensate for sea urchin grazing. Furthermore, these species are probably favored by the absence of other competitively superior species, such as the articulated coralline Corallina elongata, which are more vulnerable to sea urchin grazing because their multiannual life cycle.

Our results also agree with previous results by Nielsen (2001, 2003), who showed that in tide pools, the absence of herbivores increased the abundance of less opportunistic and more anatomically complex algal functional groups, and this effect was greater with increasing nutrients. By contrast, when herbivores were present, algal abundance was lower, with a dominance of the more opportunistic and ephemeral groups, with no effect of nutrients. In our experiment, the bottom-up effects were higher in the nonherbivore plots, since the oscillations of the algal assemblage caused by seasonal fluctuations of nutrients and light availability appeared to be greater in the absence of sea urchins.

\section{Top-down vs. bottom-up: a synthetic model}

Ballesteros (1991) proposed a conceptual model where algal assemblage structure in the northwest Mediterranean oscillates seasonally as a consequence of several bottom-up factors (i.e., light, nutrient availability, temperature). More recently, McClanahan and Sala (1997) developed an energy-based model based on topdown control with two successional extremes (sea urchin barrens vs. fleshy algal communities), which explains general dynamics at larger scales, ignoring variation in primary productivity and seasonality. Our study integrates these two different approaches, illustrating how herbivory and seasonality can interact in a complex way to shift the composition of the algal assemblages.

Although the effects of grazers and seasonality on total algal cover are independent, each individual algal species responds strongly to one of these factors, and this response is predictable in a coarse sense within algal functional groups (annual vs. perennial vs. ephemeral). Furthermore, these effects are maintained over time, thus transmitting seasonal effects of herbivory in a multiannual scale.

Because maintaining the experimental conditions was logistically very difficult and extremely time consuming, we could not replicate the experiments in other Mediterranean localities. We believe, however, that our conclusions are generally applicable to the northwestern Mediterranean. To generalize from our results to other temperate communities may be appealing because different responses to herbivores of different algal species, depending on their functional group, is a 
common trait, and periodic fluctuations in resource availability are also common in all temperate communities. However, we believe that the relative role of herbivores vs. resources will shift across a gradient of primary productivity. In the oligotrophic (e.g., Mediterranean) end of the gradient, herbivory is more likely to play a major role in determining total algal biomass. In the more productive end of the gradient (e.g., the Pacific coast of North America), bottom-up control is more likely to determine the structure and dynamics of algal communities, because algal productivity is mostly regulated by the oceanographic climate (Dayton et al. 1992, 1999), and herbivores generally have low per capita consumption rates (e.g., Jones 1971, Sala and Graham 2002) and probably have little impact on algal standing stock, except during population explosions of grazers (Jones 1971, Tegner and Dayton 1987, Graham 2002) or when algae are small in size (e.g., Harris et al. 1984, Sala and Graham 2002).

\section{ACKNOWLedgments}

Many people helped us in this study in many aspects, mostly with fieldwork. We are very grateful to all, and especially to C. Linares, D. Diaz, and J. M. Llenas for their continued support, to E. Ballesteros for discussions and guidance in the study of algal assemblages, and to M. Graham, X. Turon, and A. Arcas for help with statistics. We also thank J. Pascual for providing oceanographic data. Special thanks also to two anonymous reviewers, who greatly improved this manuscript with appropriate and constructive comments and suggestions. The City Hall of Torroella de Montgrí provided us with space and equipment at the Centre Cultural El Català. This study was funded by grant MAR1999-0526 from the Spanish Department of Education and Science, and by the Department of the Environment of the Catalan Government.

\section{Literature Cited}

Abrams, P. A., B. A. Menge, G. G. Mittelbach, D. Spiller, and P. Yodzis. 1996. The role of indirect effects on food webs. Pages 371-395 in G. Polis and K. Winemiller, editors. Food webs: dynamics and structure. Chapman and Hall, New York, New York, USA

Ballesteros, E. 1989. Production of seaweeds in Northwestern Mediterranean marine communities: Its relation with environmental conditions. Scientia Marina 53:357-364.

Ballesteros, E. 1991. Structure and dynamics of North-Western Mediterranean phytobenthic communities: a conceptual model. Pages 223-242 in J. Ros and N. Prat, editors. Homage to Ramon Margalef, or why there is such pleasure in studying nature. Publicacions de la Universitat de Barcelona, Barcelona, Spain.

Ballesteros, E. 1992. Els vegetals i la zonació litoral: espècies, comunitats i factors que influeixen en la seva distribució. Arxius de la Secció de Ciències CI, Institut d'Estudis Catalans, Barcelona, Spain.

Bayle, J. T., C. Valle, and A. Verdú. 2001. EcoCEN v.1.00: application for managing fish visual counts. Informes y Estudios COPEMED No. 7. Food and Agriculture Organization-Agencia Española de Cooperación. Internacional (FAO-AECI). 〈www.fao.copemed.org

Benedetti-Cecchi, C. L., and F. Cinelli. 1995. Habitat heterogeneity, sea urchin grazing and the distribution of algae in littoral rock pools on the west coast of Italy (western Mediterranean). Marine Ecology Progress Series 126:203212.
Broitman, B. R., S. A. Navarrete, F. Smith, and S. D. Gaines. 2001. Geographic variation of southeastern Pacific intertidal communities. Marine Ecology Progress Series 224:21-34.

Burkepile, D. E., and M. E. Hay. 2006. Herbivore vs. nutrient control of marine primary producers: context-dependent effects. Ecology 87:3128-3139.

Bustamante, R. H., G. M. Branch, S. Eekhout, B. Robertson, P. Zoutendyk, M. Schleyer, A. Dye, N. Hanekom, D. Keats, M. Jurd, and C. McQuaid. 1995. Gradients of intertidal primary productivity around the coast of South Africa and their relationships with consumer biomass. Oecologia 102: 189-201.

Clarke, K. R. 1993. Non-parametric multivariate analyses of changes in community structure. Australian Journal of Ecology 18:117-143.

Cubit, J. D. 1984. Herbivory and the seasonal abundance of algae on a high intertidal rocky shore. Ecology 65:1904-1917.

Dayton, P. K., M. Tegner, P. B. Edwards, and K. L. Riser. 1999. Temporal and spatial scales of kelp demography: the role of oceanographic climate. Ecological Monographs 69: 219-250.

Dayton, P. K., M. J. Tegner, P. E. Parnell, and P. B. Edwards. 1992. Temporal and spatial patterns of disturbance and recovery in a kelp forest community. Ecological Monographs 62:421-445.

Duffy, J. E., and M. A. Hay. 2000. Strong impacts of grazing amphipods on the organization of a benthic community. Ecological Monographs 70:237-263.

Floeter, S. R., M. D. Behrens, C. E. L. Ferreira, M. J. Paddack, and M. H. Horn. 2005. Geographical gradients of marine herbivorous fishes: patterns and processes. Marine Biology 147:1435-1447.

Fretwell, S. D. 1977. The regulation of plant communities by food chains exploiting them. Perspectives in Biology and Medicine 20:169-185.

García-Rubies, A. 1996. Estudi ecològic de les poblacions de peixos sobre substrat rocós a la Mediterrània Occidental: Efecte de la fondària, el substrat, l'estacionalitat i la protecció. Dissertation. Universitat de Barcelona, Barcelon, Spain.

García-Rubies, A. 1999. Effects of fishing on community structure and on selected populations of Mediterranean coastal reef fish. Naturalista Siciliano 23:59-81.

García-Rubies, A., and M. Zabala. 1990. Effects of total fishing prohibition on the rocky fish assemblages of Medes Islands Marine Reserve (NW Mediterranean). Scientia Marina 54: 317-328.

Graham, M. H. 2002. Prolonged reproductive consequences of short-term biomass loss in seaweeds. Marine Biology 140: 901-911.

Graham, M. H., and M. S. Edwards. 2001. Statistical significance versus fit: estimating the importance of individual factors in ecological analysis of variance. Oikos 93:505-513.

Hairston, N. G., F. E. Smith, and L. B. Slobodkin. 1960. Community structure, population control, and competition. American Naturalist 94:421-425.

Harmelin-Vivien, M. L., J. Harmelin, C. Chauvet, C. Duval, R. Galzin, P. Lejeune, G. Barnabé, F. Blanc, R. Chevalier, J. Cucler, and G. Lasserre. 1985. Evaluation visuelle des peuplements et populations de poissons; methodes et problemes. Révue d'Ecologie (Terre et Vie) 40:467-539.

Harris, L. G., A. W. Ebeling, D. R. Laur, and R. J. Rowley. 1984. Community recovery after storm damage: a case of facilitation in primary succession. Science 224:1336-1338.

Hereu, B. 2005. Movement patterns of the sea urchin Paracentrotus lividus in a marine reserve and an unprotected area in the NW Mediterranean. Marine Ecology 26:54-62.

Hereu, B. 2006. Depletion of palatable algae by sea urchins and fishes in the Mediterranean subtidal community. Marine Ecology Progress Series 313:95-103. 
Hereu, B., C. Linares, M. Zabala, and E. Sala. 2004. The effects of predator abundance and habitat structural complexity on survival of juvenile sea urchins. Marine Biology 146:243-249.

Hughes, T. P., et al. 2003. Climate change, human impacts, and the resilience of coral reefs. Science 301:929-933.

Hunter, M. D., and P. W. Price. 1992. Playing chutes and ladders: heterogeneity and the relative roles of bottom-up and top-down forces in natural communities. Ecology 73:724-732.

Jones, L. G. 1971. The biology of giant kelp beds (Macrocystis) in California: studies on selected small herbivorous invertebrates inhabiting Macrocystis canopies and holdfasts in southern Californian kelp beds. Nova Hedwigia 32:343-367.

Kaehler, S., and G. A. Williams. 1998. Early development of algal assemblages under different regimes of physical and biotic factors on a seasonal tropical rocky shore. Marine Ecology Progress Series 172:61-71.

Legendre, P., and L. Legendre. 1998. Numerical ecology. Elsevier Science BV, Amsterdam, The Netherlands.

Leonard, G. H., J. M. Levine, P. R. Schmidt, and M. D. Bertness. 1998. Flow-driven variation in intertidal community structure in a Maine estuary. Ecology 79:1395-1411.

Leps, J., and P. Smilauer. 2003. Multivariate analysis of ecological data using CANOCO. Cambridge University Press, New York, New York, USA.

Lubchenco, J., and J. Cubit. 1980. Heteromorphic life histories of certain marine algae as adaptations to variations in herbivory. Ecology 61:333-344.

Lubchenco, J., and S. D. Gaines. 1981. A unified approach to marine plant-herbivore interactions. I. Populations and communities. Annual Review of Ecology and Systematics 12:405-437.

McClanahan, T. R., and E. Sala. 1997. A Mediterranean rockybottom ecosystem fisheries model. Ecological Modelling 104: $145-164$.

Menge, B. A. 2000. Top-down and bottom-up community regulation in marine rocky intertidal habitats. Journal of Experimental Marine Biology and Ecology 250:257-289.

Menge, B. A., C. Blanchette, P. Raimondi, T. Freidenburg, S. Gaines, J. Lubchenco, D. Lohse, G. Hudson, M. Foley, and J. Pamplin. 2004. Species interaction strength: testing model predictions along an upwelling gradient. Ecological Monographs 74:663-684.

Menge, B. A., B. A. Daley, P. A. Wheeler, E. Dahlhoff, E. Sanford, and P. T. Strub. 1997. Benthic-pelagic links and rocky intertidal communities: Bottom-up effects on topdown control? Proceedings of the National Academy of Sciences (USA) 94:14530-14535.

Menge, B. A., et al. 2003. Coastal oceanography sets the pace of rocky intertidal community dynamics. Proceedings of the National Academy of Sciences (USA) 100:12229-12234.

Nielsen, K. J. 2001. Bottom-up and top-down forces in tide pools: test of a food chain model in an intertidal community. Ecological Monographs 71:187-217.

Nielsen, K. J. 2003. Nutrient loading and consumers: agents of change in open-coast macrophyte assemblages. Proceedings of the National Academy of Sciences (USA) 100:7660-7665.

Nielsen, K. J., and S. A. Navarrete. 2004. Mesoscale regulation comes from the bottom-up: intertidal interactions between consumers and upwelling. Ecology Letters 7:31-41.

Pace, M. L., J. J. Cole, R. C. Carpenter, and J. F. Kitchell. 1999. Trophic cascades revealed in diverse ecosystems. Trends in Ecology and Evolution 14:483-488.

Peirano, A., I. Niccolai, R. Mauro, and C. N. Bianchi. 2001. Seasonal grazing and food preference of herbivores in a Posidonia oceanica meadow. Scientia Marina 65:367-374.

Polis, G. A. 1999. Why are parts of the world green? Multiple factors control productivity and the distribution of biomass. Oikos 86:3-15.

Power, M. E. 1992. Top-down and bottom-up forces in food webs: do plants have primacy? Ecology 73:733-746.
Prado, P., F. Tomas, T. Alcoverro, and J. Romero. 2007. Extensive direct measurements of Posidonia oceanica defoliation confirm the importance of herbivory in temperate seagrass meadows. Marine Ecology Progress Series 340:6371.

Ruitton, S., P. Francour, and C. F. Boudouresque. 2000. Relationship between algae, benthic herbivorous invertebrates and fishes in rocky sublittoral communities of a temperate sea (Mediterranean). Estuarine, Coastal and Shelf Science 50:217-230.

Sala, E. 1996. The role of fishes in the organization of a Mediterranean subtidal community. Dissertation. Université d'Aix-Marseille II, Aix-en-Provence, France.

Sala, E. 1997a. The role of fishes in the organization of a Mediterranean sublittoral community II: epifaunal communities. Journal of Experimental Marine Biology and Ecology 212:45-60.

Sala, E. 1997b. Fish predators and scavengers of the sea urchin Paracentrotus lividus in protected areas of the north-west Mediterranean Sea. Marine Biology 129:531-539.

Sala, E., and E. Ballesteros. 1997. Partitioning of space and food resources by three fish of the genus Diplodus (Sparidae) in a Mediterranean rocky infralittoral ecosystem. Marine Ecology Progress Series 152:273-283.

Sala, E., and C. F. Boudouresque. 1997. The role of fishes in the organization of a Mediterranean sublittoral community I: Algal communities. Journal of Experimental Marine Biology and Ecology 212:25-44.

Sala, E., C. F. Boudouresque, and M. Harmelin-Vivien. 1998. Fishing, trophic cascades, and the structure of algal assemblages: evaluation of an old but untested paradigm. Oikos 82:425-439.

Sala, E., and M. H. Graham. 2002. Community-wide distribution of predatory-prey interaction strength in kelp forests. Proceedings of the National Academy of Sciences (USA) 99: 3678-3683.

Sala, E., and M. Zabala. 1996. Fish predation and the structure of the sea urchin Paracentrotus lividus populations in the NW Mediterranean. Marine Ecology Progress Series 140:71-81.

Salat, J., and J. Pascual. 2002. The oceanographic and meteorological station at l'Estartit (NW Mediterranean). CIESM Workshop series 16:29-32.

Schmitz, O. J., A. P. Beckerman, and K. M. O’Brien. 1997. Behaviorally mediated trophic cascades: effects of predation risk on food web interactions. Ecology 78:1388-1399.

Souza, W. P. 1979. Experimental investigations of disturbance and ecological succession in a rocky intertidal algal community. Ecological Monographs 49:227-254.

Steneck, R. S., and E. Sala. 2005. Large marine carnivores: trophic cascades and top-down controls in coastal ecosystems past and present. Pages 110-137 in J. C. Ray, K. H. Redford, R. S. Steneck, and J. Berger, editors. Conserving predation: relationships between large carnivorous animals and biodiversity. Island Press, Washington, D.C., USA.

Tegner, M. J., and P. K. Dayton. 1987. El Niño effects on Southern California kelp forest communities. Advances in Ecological Research 17:243-279.

ter Braak, C. J. F. 1994. Canonical community ordination. Part 1: basic theory and linear methods. Ecoscience 1:127-140.

ter Braak, C. J. F., and P. Smilauer. 1998. CANOCO for Windows Version 4.0. Centre for Biometry, CPRO-DLO, Wageningen, The Netherlands.

Tomas, F., X. Turon, and J. Romero. 2005. Seasonal and small-scale spatial variability of herbivory pressure on the temperate seagrass Posidonia oceanica. Marine Ecology Progress Series 301:95-107.

Trussell, G. C., P. J. Ewanchuk, and M. D. Bertness. 2003. Trait-mediated effects in rocky intertidal food chains: predator risk cues alter prey feeding rates. Ecology 84:629640. 
Underwood, A. J. 1981. Structure of rocky intertidal community in New South Wales: patterns of vertical distribution and seasonal changes. Journal of Experimental Biology and Ecology 51:57-85.

Verlaque, M. 1987. Relations entre Paracentrotus lividus (Lamarck) et le phytobenthos de Méditerranée occidentale. Pages 5-36 in C. F. Boudouresque, editor. Colloque international sur Paracentrotus lividus et les oursins comestibles. GIS Posidonie Publications, Marseille, France.

von Ende, C. N. 1993. Repeated-measures analysis: growth and other time-dependent measures. Pages $113-137$ in S. M.
Schneider and J. Gurevitch, editors. Design and analysis of ecological experiments. Chapman and Hall, New York, New York, USA.

Weinberg, S., and A. Cortel-Breeman. 1978. The estimation of yearly cycle of submarine irradiance for ecological purposes. A methodological example based on data from Banyuls sur Mer. Bijdragen tot de Dierkunde 48:35-44.

Worm, B., H. K. Lotze, H. Hillebrand, and U. Sommer. 2002. Consumer versus resource control of species diversity and ecosystem functioning. Nature 417:848-851.

\section{APPENDIX A}

Location of study sites, inside Medes Islands protected area, northeast Spain, and northwest Mediterranean Sea (Ecological Archives E089-196-A1).

\section{APPENDIX B}

Fish species censused in the experimental areas (Ecological Archives E089-196-A2).

\section{APPENDIX C}

Major benthic algal species in the study assemblage (Ecological Archives E089-196-A3).

\section{APPENDIX D}

Density of the sea urchin Paracentrotus lividus in the experimental treatments over time (Ecological Archives E089-196-A4).

\section{APPENDIX E}

Monthly average data of nutrient concentration and temperature, and estimated irradiance at $5 \mathrm{~m}$ depth at Medes Islands Marine Reserve during the study period (Ecological Archives E089-196-A5).

\section{APPENDIX F}

Average biomass of the most abundant benthic feeding fishes inside and outside the experimental exclosures (Ecological Archives E089-196-A6).

\section{APPENDIX G}

Temporal changes in the percent cover of algal taxa over time (Ecological Archives E089-196-A7).

\section{APPENDIX H}

Temporal variation in cover of algal species measured during the experiment (Ecological Archives E089-196-A8).

\section{APPENDIX I}

Results of redundancy analysis on algal cover data, and environmental and experimental variables (Ecological Archives E089196-A9).

\section{APPENDIX J}

Principal components analysis (Ecological Archives E089-196-A10). 